\title{
Experimental Platform Development of Similar Simulation and Mechanical Test for Undersea Metal Mining
}

\author{
Zhixiang Liu ${ }^{1}$, Xiaoqing Dai ${ }^{1}$, Shan Yang ${ }^{1 *}$, Yuxi Liu ${ }^{2}$ \\ ${ }^{1}$ School of Resources and Safety Engineering, Central South University, Changsha 410083, China; \\ ${ }^{2}$ Engineering faculty, Monash University, Melbourne 3800, Australia
}

\begin{abstract}
With the depletion of shallow metal resources in the land, the development of seabed resources has become a new direction. In order to achieve safe and efficient exploitation of seabed metal mineral resources, a similar simulation test platform was established for seabed mining of metal minerals in this paper. Similar simulation materials and the best material ratios were selected to make simulated specimens. A series of mechanical pressurization devices and model sample were prototyped and submarine simulation mining test was conducted. During the simulation mining test, stress and strain changes and microscopic observations of crack evolution were monitored by the static strain test system. These indicators revealed the characteristics of ore-rock mechanical change in the development of submarine mental resources. By exploring the best safe thickness of seabed resource mining, it provides effective data reference for subsequent seabed resource development, so as to realize safe and efficient mining.
\end{abstract}

\section{Introduction}

After nearly 50 years of exploitation, China's shallow metal resources in the land have been greatly mined. Subsequently, the cost of deep mining and the difficulty in mining technology have increased obviously. The sea-based resources, which are dominated in China's coastal and continental shelf, have provided a new outlet and direction for the development of China's metal mineral resources. There are a large number of metal deposits in the submarine continental shelf with high mining efficiency, which can greatly alleviate the shortage of mineral resources in China and meet the demand of metal resources for national economic construction. However, the seafloor on the submarine metal mine is seawater, so the mining has certain difficulties. Besides, most submarine bedrock metal deposits are inclined or steeply inclined thick ores. If the deformation of the mining rock cannot be effectively controlledor the movement law of rock cannot be mastered, water inrush can be caused by sea water penetration through the fracture zone, causing major safety accidents [1]. Therefore, the safety insulation thickness from mining layer to the seabed is a critical issue for subsea mining, and it is necessary to carry out relevant theoretical researches on the seabed mining of metal ores on the basis of mining characteristics of seafloor metal ores [2].

Recently, coal mining has been widely used in deep-sea mineral exploration, while the progress of sub-sea metal mines is relatively rare. Major mining sites out of China include Krowa iron mines in Finland, Newfoundland iron mines in Canada, Levent nickel mines in the United Kingdom and Dove tungsten in Australia. Sanshandao gold mine is the first subsea metal mine in China [3]. For the key technical problem of mine water inrush caused by subsea mining, many domestic and foreign scholars have conducted a lot of theoretical researches. Domestically, $\mathrm{Li}$ et al. proposed a three-dimensional dynamic simulation method of mine water inrush process, and established a dynamic simulation model of crack evolution in mine water inrush process [4]. Ma et al. used numerical simulation methods to analyze the stress and plasticity distribution law of the surrounding rock and karst collapse mining with pressure, and revealed the formation mechanism of the water inrush channel in the karst collapse-bearing roof [5]. According to Ding et al. [6], the fault zone, as a low-strength zone in the rock mass, affected by excavation of ore bodies often generates fault activation and becomes a water inrush channel. Therefore, numerical simulation methods have been applied to study the activation of fracture zones and the mechanism of water inrush in mining of seabed deposits. Kesseru put forward three models of mine water inrush using empirical methods and hydraulic fracturing methods. Through experiments, the rational size of the pillars to prevent water inrush was explored, and the relationship between the mine seepage pressure and the thickness of the pillars was revealed. Rational mine pillar size was designed for the mine, which provides a theoretical basis [7]. All the above research results show that water inrush

*corresponding author, Email addresses: Shan Yang.yangshan@csu.edu.cn, Xiaoqingdai,963968303@qq.com 
in mining is caused by the rock strata deformation and cracks expansion.

To this end, the materials that meet the water-infusion damage were selected and prepared as specimens based on the mining characteristics of the bedrock. Through similar simulation experiments, evolution rules of overburden deformation and fracture were explored in seabed mining, revealing the inoculating mechanism of water inrush in undersea mining of metal ore. Water inrush criteria for seabed metal ore mining were established and a reasonable thickness of the mining isolation layer was proposed in this paper, so as to provide a theoretical basis for China's safe mining of seabed metal ore deposits.

\section{Determination of similar simulation test materials}

\subsection{Selection of material}

The similar materials, which were used for the multi-phase coupling simulation in underground rock mass engineering, should have the following characteristics: large bulk density, low strength and stable performance. According to the similarity theory, relevant materials selection principle, the solid paraffin and liquid paraffin was finally selected as binding agents, Hesha and barite powder as aggregates in this research, among which the liquid paraffin was mainly used to control the plasticity of the material, the paraffin wax was used to control the non-hydrophilic of the material, and the barite powder was used to adjust the bulk density [8]. At the beginning of the study, some prepared specimens have been placed in water for 3 days and 7 days [9], and unimmersed specimens were tested. The test results are shown in Table 1.

Table 1 Mechanical Parameters

\begin{tabular}{ccccc}
\hline $\begin{array}{c}\text { Sample } \\
\text { soaking } \\
\text { time/d }\end{array}$ & $\begin{array}{c}\text { Density/ } \\
\mathrm{kg} / \mathrm{m}^{3}\end{array}$ & $\begin{array}{c}\text { Elastic } \\
\text { Modulus/ } \\
\mathrm{MPa}\end{array}$ & $\begin{array}{c}\text { Compressive } \\
\text { strength/MPa }\end{array}$ & $\begin{array}{c}\text { Tensile } \\
\text { strength } \\
/ \mathrm{MPa}\end{array}$ \\
\hline 0 & 2706 & 358.26 & 3.94 & 0.26 \\
3 & 2709 & 353.17 & 3.98 & 0.23 \\
7 & 2708 & 362.48 & 3.95 & 0.25 \\
\hline
\end{tabular}

Results show that whether the specimens are immersed, or the immersion time has no influence on the mechanical parameters of the specimen. Besides, it is found that the model specimen can meet the requirement that the shape of the crushed rock remains unchanged when the simulated gushing water seepage along the fracture, indicating the experiment material selection is feasible.

\subsection{Similar model parameters test}

This model was made of a cast iron template with a geometric dimension of $70.7 \mathrm{~mm} \times 70.7 \mathrm{~mm} \times 70.7 \mathrm{~mm}$. Uniaxial compressive strength tests and splitting tests were performed on each set of specimens with different proportions on the uniaxial compression instrument. The measured parameters of the specimens are shown in Table 2.

Table 2 Specimen parameter

\begin{tabular}{ccccc}
\hline $\begin{array}{c}\text { Matching Density } \\
\text { number }\end{array}$ & $\begin{array}{c}\text { Elastic } \\
\text { Modulus } \\
/ \mathrm{kg} / \mathrm{m}^{3}\end{array}$ & $\begin{array}{c}\text { Compressive } \\
\text { strength } \\
/ \mathrm{MPa}\end{array}$ & $\begin{array}{c}\text { Tensile } \\
\text { strength } \\
/ \mathrm{MPa}\end{array}$ \\
\hline 2110 & 2706 & 351.14 & 5.64 & 0.35 \\
1191 & 2542 & 313.63 & 4.84 & 0.29 \\
1273 & 2143 & 215.36 & 2.91 & 0.18 \\
2164 & 2698 & 145.26 & 3.95 & 0.27 \\
1146 & 2523 & 131.15 & 2.97 & 0.23 \\
1228 & 2098 & 63.24 & 1.13 & 0.17 \\
\hline
\end{tabular}

The full stress-strain curve of the model material specimen is shown in Figure 1. The full stress-strain curve of the rock is very similar to that of the rock.

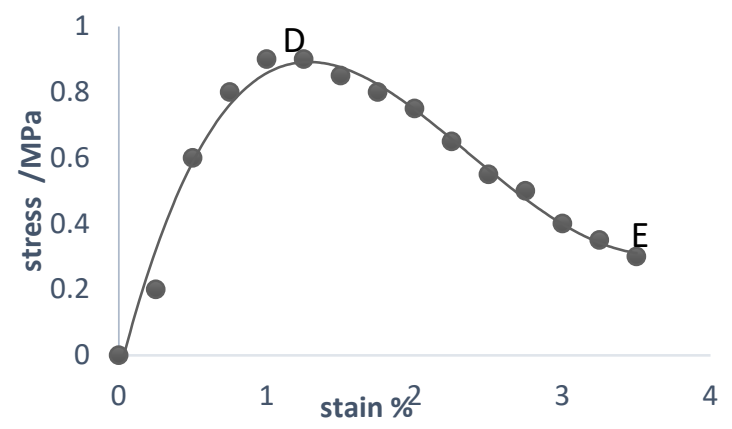

Figure 1 Full stress-strain curve of specimen material

\subsection{Analysis of material ratio results}

Through a large number of proportioning tests, influence curves of each material content on the performance of specimens were analyzed[8]. The effect of different proportions on the specimen's aggregate are shown in Figure 2 and Figure 3.

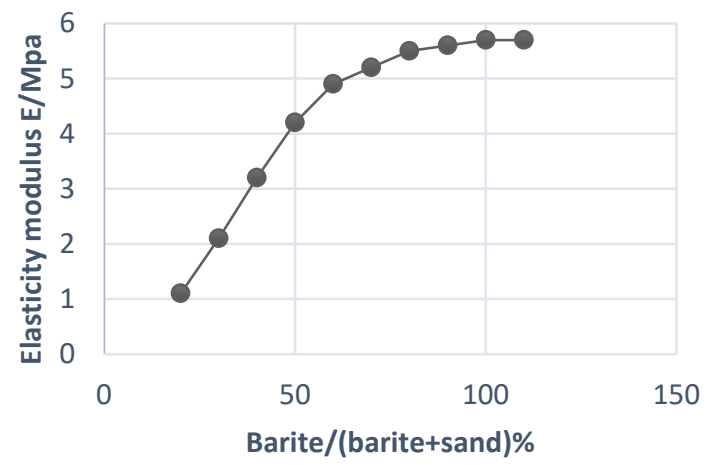

Figure 2 Elasticity modulus-barite relationships 


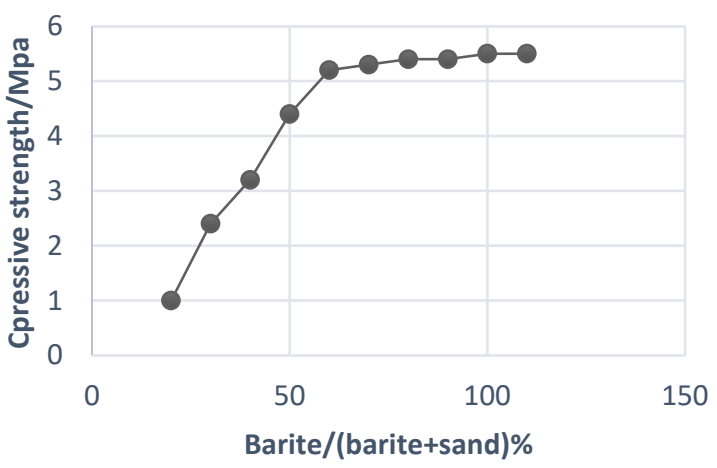

Figure 3 Compressive strength-barite relationships

As shown in the figure, as the increasing content of barite powder in the aggregate, the material density, elastic modulus, compressive strength, and tensile strength increase significantly within a certain range.However, the relationship is non-linear. In addition, when the amount of aggregates remains and the proportion of paraffin wax in the cement increases, the density of the specimen slightly increases. The compressive strength has little change within a certain range, but a significant increase within another range.

\subsection{Simulation of lithology}

The physical and mechanical parameters of the original rock in the site are listed as follows: the bulk density is $2.619 \mathrm{kN} / \mathrm{m} 3$, the compressive strength is $134.94 \mathrm{MPa}$ and the elastic modulus is $7.53 \times 103 \mathrm{MPa}$. The similarity criteria derived from the similarity theory can be expressed as:

$$
\begin{aligned}
\frac{c_{\sigma}}{\mathcal{C}_{l} c_{\gamma}} & =1 \\
\frac{\mathcal{C}_{E}}{\mathcal{C}_{l} \mathcal{C}_{\gamma}} & =1
\end{aligned}
$$

The geometric similarity ratio used in the subsequent geomechanical model test is $\mathrm{Cl}=200$. The data in Table 3 is substituted as the similarity criterion, the test result of the ratio 1228 can greatly agree with the similarity criteria, as:

$$
\begin{aligned}
& \frac{\mathcal{C}_{\sigma}}{\mathcal{C}_{l} \mathcal{C}_{\gamma}}=0.957 \\
& \frac{\mathcal{C}_{E}}{\mathcal{C}_{l} \mathcal{C}_{\gamma}}=1.081
\end{aligned}
$$

Therefore, this ratio is considered as the most suitable material ratio for simulating the original rock. Namely, the mass ratio of barite powder to river sand is $1: 2$, and the solid-liquid ratio is 1:4.

\section{Development of the Similar Simulation Test Platform}

In view of the complex stress conditions of mining wells in undersea ore bodies, this experiment developed a large-scale model test platform for the mechanism of water inrush from submarine orebodies. The model test platform successfully addressed the issue of the fluid-solid coupling model. The problem of sealing between the model box and the specimen in the test was solved, and the top hydraulic pressure loading was used to solve the defect of the uneven top loading pressure in the conventional model. The top of the model box was loaded with direct servo hydraulic pressure, and the two sides were loaded with servo hydraulic loading to simulate the process of water inrush under the combined action of complex ground stress, water pressure and mining impact. In the end, the system adopted an on-site microscope to observe the occurrence, development and destruction of cracks, and employed advanced measurement equipment based on the digital image analysis of displacement, so that mechanism tests of water inrush were conducted from the macro and micro levels.

\subsection{Similar Simulation Mechanics Test}

A similarity ratio of 1:200 was used in this study. The excavation process was completed in 10 steps, gradually digging from the middle to both sides, each about 0.04 meters. Mining environment was set as 10 meters above the seawater and 35 meters below the sea mud. The device layout is shown in Figure 4. Horizontal lateral pressure loading system is adopted, and the top water pressure is gradually increased to supply the lateral pressure and vertical pressure. To monitor the test process, the epoxy resin was used to fix the strain gauge and acoustic emission probe on the surface of the model, then the strain gauges were used to connect the DH3816 static strain test system and the PCI-2 acoustic emission device. The similar physical model test system of submarine open-mining rock mechanics consists of test bench, hydraulic servo pump station, horizontal and vertical pressure servo loading device, top water pressure servo loading device, control measurement analysis software and other measuring devices [10].
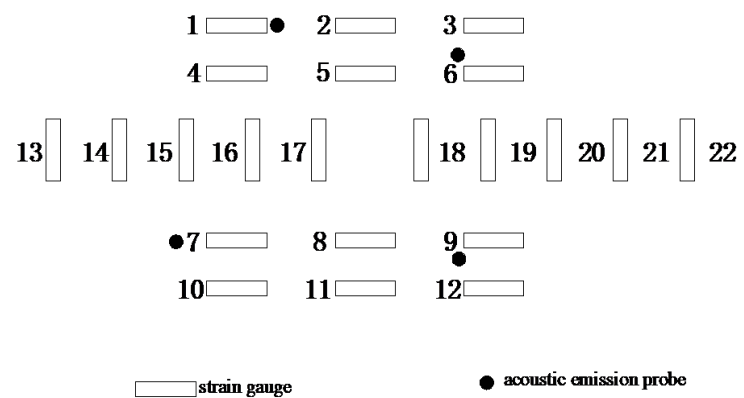

Figure 4 Acoustic emission probe and strain gauge layout for similar simulation experiments

As shown in Figure 5, in addition to the automatic recording of test data and test curves, the entire test system is equipped with observation devices for cracks and displacements. Crack observations were observed by using a stereomicroscope. Displacement observations were based on digital image analysis without punctuation. 


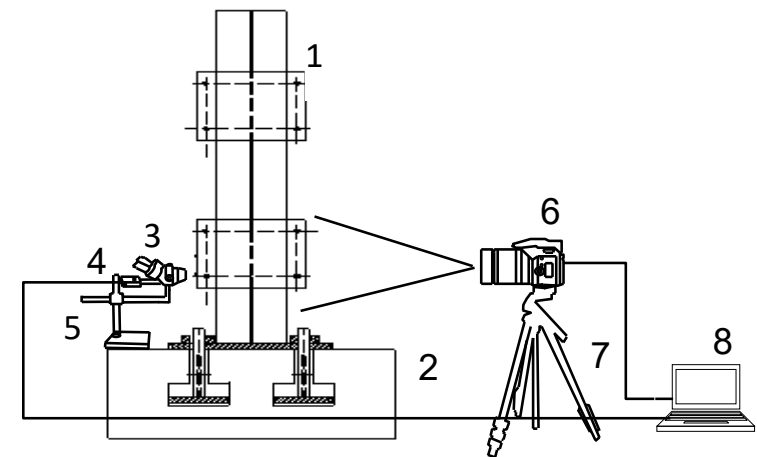

1-Inverse Forces; 2-Test Benches; 3-Digital Microscopes; 4-Digital Cameras; 5-Side Microscope Bearings; 6-Digital Camera; 7-Digital Camera Stand; 8-Computer

Figure 5 Schematic diagram of measuring device layout

During the test, the test model was first built in the model box with a certain similarity ratio, then it was loaded as the designed loading mode [11]. Firstly, horizontal side pressure loading system determined the lateral pressure on both sides of the model components; after the model box was sealed, the vertical water pressure determined by the vertical pressure loading system was applied; the observation devices for cracks and displacement were arranged. Then the mining process was simulated according to the general mining steps. After the simulated mining, if no water inrush occurred, the vertical pressure could be increased or the pressure on both sides of the model could be adjusted during the test, till the water inrush occurred in the model. Under the conditions of vertical pressure and lateral pressure, the critical water inrush height for water inrush, the distribution of model cracks and displacement after each construction step can be obtained in the model test.

\subsection{Analysis of experimental results}

Through a series of loading and inspection by the monitoring device, the process diagram of the excavation was simulated step by step. It was found that in the tenth step of excavation, namely, when the excavation span reached $0.4 \mathrm{~m}$, the water passed through the fracture along the top plate. After 10 steps of continuous excavation, the water inrush was formed. According to the test results, the similarity ratio and the safe thick-span ratio formula $(\mathrm{H} \geq 0.5 \mathrm{nW}, \mathrm{n}$ is the safety factor of $1.0, \mathrm{~W}$ is the stop-field span) could be obtained. When the thickness of the roof exceeded $40 \mathrm{~m}$, water inrush could not occur in the rock layer. If it less than $40 \mathrm{~m}$, water inrush characteristics appear in the roof rock formation. In addition, digital photography technology was developed to compile software to process the displacement cloud map in the excavation process. A part of the cloud is shown in Figure 6.

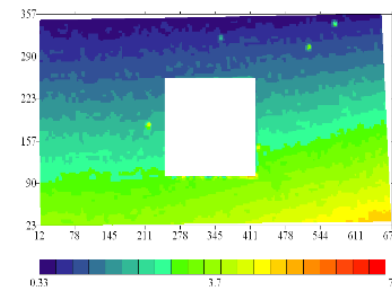

(1)

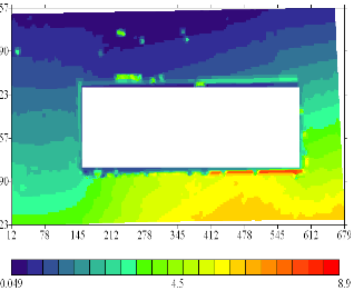

(2)
Figure 6 Displacement cloud map based on digital photographic analysis

(1)- Displacement cloud after the third excavation step;

(2)- Displacement cloud after the ninth excavation step

Through cloud image analysis, it can be found that as the excavation proceeds, the settlement displacement of the stope roof increases continuously.According to the test results and the analysis of the safe-thickness-span-ratio formula, when the continuous slab excavation is carried out with the thickness of the roof less than $40 \mathrm{~m}$, the tensile strain in the roof of the model increases significantly, and pull failure occurs [12] In order to monitor the displacement of key points during the test, nine monitoring points were specially set up, and the displacement was monitored in real time by the dial indicator. Figure 7 and Figure 8 illustrate monitoring results of the top four monitoring points and the bottom five monitoring points of the stope in the similar simulation experiment.

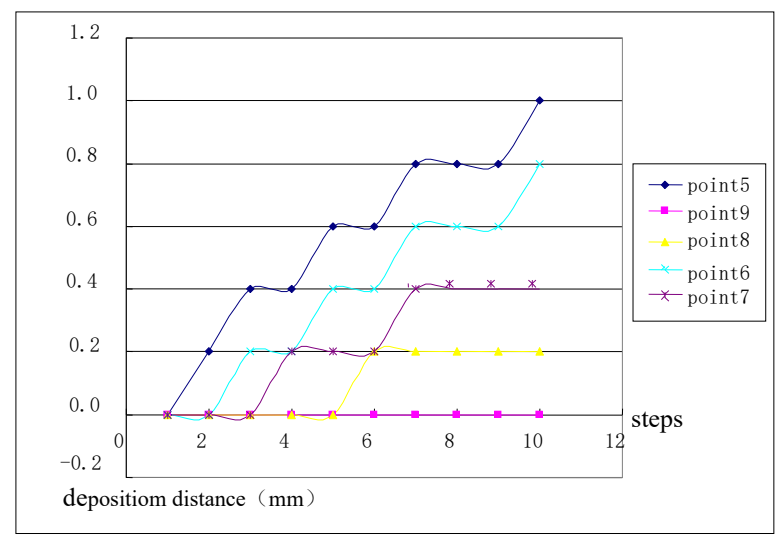

Figure 7 Monitoring results at the top four monitoring points

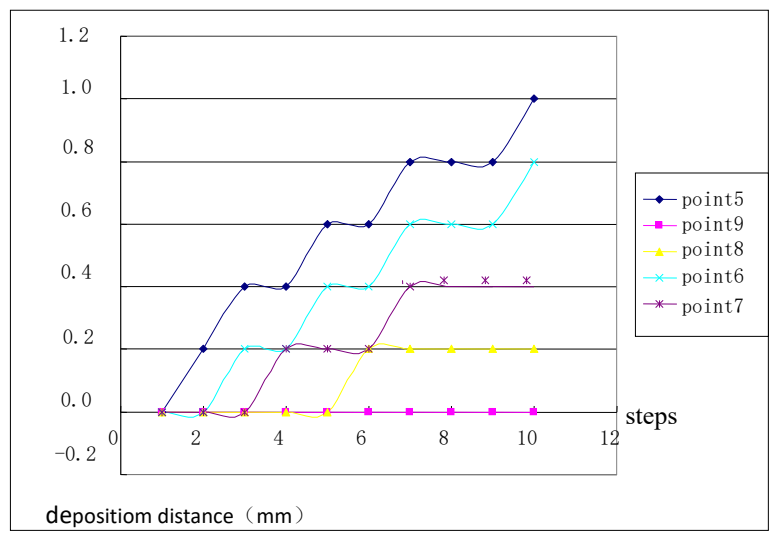

Figure 8 Monitoring results of four monitoring bottom points 


\section{Numerical simulation verification}

In this experiment, FLAC3D numerical simulation method was used to simulate the mechanical state and changes of the rock mass in the mining area under the mining disturbance. Finally, the stress field, displacement field and destruction field of the ore body and the surrounding rock in different mining stages were obtained. In the numerical simulation, the compressive stress was negative while the tensile stress was positive; the shear stress was conducted counterclockwise positive and clockwise negative; it was positive when the displacement was the same as the axis direction, and it was negative when the direction of the axis is the same. FLAC3D automatically processed calculation results to obtain the final stress field, displacement field and out of plasticity distribution map .

\subsection{Stress field analysis}

Through the maximum principal stress distribution shown by FLAC3D, it was found that the maximum principal stress gradually increased from top to bottom in the deposit model. According to the tensile stress distribution on the seabed, there was tensile stress on the seabed below the level of $-95 \mathrm{~m}$, mining to the $-85 \mathrm{~m}$ level, or localized tensile stress on the seabed. After mining to the $-75 \mathrm{~m}$ level, the tensile stress on the seabed increased significantly. The distribution of strips showed that ore deposits were damaged on the level of $-75 \mathrm{~m}$. Similarly, according to the minimum principal stress distribution map, it is found that the minimum principal stress, which increased with the increasing depth in the surrounding rock of the stope, was small near the seabed of $2 \mathrm{MPa}$. The minimum value of the principal stress varied from about 16 to $24 \mathrm{MPa}$ and increased with the increase of recovery steps.

\subsection{Displacement field distribution}

Based on FLAC3D simulation results, X-displacement analysis is taken as an example, the displacement in the $\mathrm{X}$-direction has two displacement concentration areas on the sea floor: one is the displacement in the positive $\mathrm{X}$-direction, and the other one is the displacement in the negative $\mathrm{X}$-direction. With the increase of recovery steps, the positive $\mathrm{X}$-direction displacement concentration area gradually extends to the right, while the negative $\mathrm{X}$-direction displacement concentration area changes little. As the recovery step increases, the displacement in the positive $\mathrm{X}$-direction increases. The calculations show that the deformation characteristics are obvious after the exploitation of the $-85 \mathrm{~m}$ level to the $-75 \mathrm{~m}$ level. The minimum $\mathrm{X}$-axis displacement is basically the same, about 2 3mm. Similarly, the displacement in the $\mathrm{Y}$-direction and the displacement in the $\mathrm{Z}$ direction can be analyzed. The displacement in the Y-direction has two displacement concentration zones on the sea floor: one is the displacement in the positive Y-direction, and the other one is the displacement in the negative Y-direction. With the increase of recovery steps, the positive $\mathrm{X}$-direction displacement concentration area and the negative $\mathrm{X}$-direction displacement concentration area gradually extend to the left and right sides. With the increase of recovery steps, the displacement in the positive Y-direction increases, and the absolute value of the negative Y-direction also increases. However, the displacement in the Y-direction has no significant displacement in the X-direction with the increase of the picking step. Studies show that the X-and Y-direction displacements increase significantly after mining to a level of $-85 m$ to $-75 m$.

\subsection{Plastic zone distribution}

According to FLAC3D simulation diagram, we can know from the results that after the first step of mining, there are certain sporadic plastic zones on the seabed, which are mainly caused by tension or shear damage; after the second step of mining, the plastic zone of the seafloor rock formation increases to a certain extent distribution; After the third step, the plastic zone of the seafloor rock formation is expanded but not connected; after the fourth step, as the mining height increases, the range of the plastic zone increases significantly and they are interconnected, indicating that the seafloor rock formation are destroyed. A variety of microscopic and macroscopic cracks are produced. These cracks continuously expand and eventually interpenetrate, and thus become seawater passages on the seabed, resulting in an increase in downhole water inflow, which will endanger the safety of the mine.

\section{Conclusions}

In this study, an indoor research model on submarine mining was conducted by, using a mechanical device to simulate the actual stress environment of subsea mining. In view of the complex mining stress of the undersea ore body, the underwater physical and mechanical testing model for similar rock mechanics can be used to complete the physical model test of the mine water inrush mechanism, considering the fluid-structure coupling effect of the horizontal and vertical water pressure. This study provided a platform for the research on the mechanism and prevention of water damage in seawater mines. This device can be used to simulate and analyze the joint action of complex stress, water pressure and mining influences, water seepage and mutation under the macroscopic and microscopic migration laws of the ore rock, so as to reveal the water inrush mechanism of the underwater mining roof. In the experiment, the static strain test system and the acoustic emission device were used to monitor the stress and strain changes in the simulated mining test process; and microscopic observations of the crack evolution in the simulated mining process were carried out; at the same time, data of numerical simulation analysis was obtained from monitoring system. Based on the numerical simulation analysis, it is found that it was reasonable to reserve the insulation layer's thickness of the top $40 \mathrm{~m}$ during subsea mining. Under the condition that the thickness of the 
safety barrier is less than $40 \mathrm{~m}$, the roof rock showed water inrush characteristics as the excavation carried out, and further mining would lead to mine water inrush accidents. This conclusion provides a powerful reference for future seabed mining to achieve safe and efficient seabed mining to a large extent.

\section{Acknowledge}

The authors wish to acknowledge financial support from the Major Scientific and Technological Innovation Projects in Shandong Province(No. 2019SDZY05) and the National Natural Science Foundation of China (No. 51974359 and No. 51674288).

\section{References}

1. Gu D.S., Li X.B. (2006) Modern mining science and technology for metal mineral resources. Beijing: China Metallurgical Industry Press. (in Chinese)

2. Zhao G.Y. (2009) Study on the safety mining technology of seabed hard rock. China Safety Science Journal, 19(5): 159-166. (in Chinese)

3. Qiao W.G., Lu Y.X., Li R. et al. (2011) Safe and high-efficiency mining of submarine metal deposit. Gold, 32(7): 30-35. (in Chinese)

4. Li C.P., Li Z.X., Zheng Y.J. et al. (2013) Three-dimensional dynamic simulation modeling of water inrushes in underground mines. Journal of University of Science and Technology Beijing, 35(2): 35-39. (in Chinese)

5. Ma D., Miao X.X., Bai H.B., Huang J.H., Pu H., Wu Y., Zhang G.M., Li J.W. (2016) Effect of mining on shear sidewall groundwater inrush hazard caused by seepage instability of the penetrated karst collapse pillar. Natural Hazards 82 (1), 73-93.

6. Ding D.M., Ma F.S., Wang C. et al. (2010) Research on activating Effects of Fault Zone induced by mining subsea orebody. The Chinese Journal of Geological Hazard and Control, 21(1): 12-15. (in Chinese)

7. Kesseru Z. (1984) Empirical and theoretical methods for designing soft semi-impermeable protective barriers. International Journal of Mine Water, 3(2): 1-12

8. Sun H.X. (1999) Prospects of undersea mining in China. China Coal, 25(8): 34-36. (in Chinese)

9. Zhang J., Hou Z.J. (2004) Experimental study on simulation materials for solid-liquid coupling. Chinese Journal of Rock Mechanics and Engineering, 23(18): 3157-3161. (in Chinese)

10. Wang Z. (2011) Analysis on mining engineering Similar Materials and Model test. Shanxi Architecture, 37(32):108-109. (in Chinese)

11. Liu A.H., Peng S.Q., Li X.B. (2009) Development and application of similar physical model experiment system for water inrush mechanism in deep mining. Chinese Journal of Rock Mechanics and Engineering, 28(7): 1335-1342. (in Chinese)

12. Wang W.Z., Pan J.K., Wang Z. et al. (2012) Analysis of metal mining technology in China. Modern Business Trade Industry, 2012(20):192-193. (in Chinese)

13. Sun X., Yang Z.R., Zhao Z.Y. (2006) Application of geomechanical analytic approach of the principal stress orientation. Chinese Journal of Geotechnical Engineering, 28(1): 81-84. (in Chinese) 